\title{
Role of Suction Drain after Knee Arthroplasty in the Tranexamic Acid Era: A Randomized Controlled Study
}

\author{
Rajesh Navin Maniar, MCh (Ortho), Prashant Pradhan, DNB*, Nishit Bhatnagar, MS, \\ Adit Maniar, $\mathrm{MBBS}^{\dagger}$, Rohan Bidwai, MS ${ }^{\ddagger}$, Pranav Bindal, MS \\ Department of Orthopaedics, Lilavati Hospital and Research Centre, Mumbai, \\ ${ }^{*}$ Department of Orthopaedics, Siddharth Municipal Hospital, Mumbai, \\ ${ }^{\dagger}$ Department of Orthopaedics, Dr. Vasantrao Pawar Medical College Hospital and Research Centre, Nashik, India, \\ ${ }^{\ddagger}$ Centre for Hip Surgery, Wrightington Hospital, Wigan, UK
}

Background: Postoperative suction drains are used after total knee arthroplasty to avoid intra-articular hematoma formation although they can increase blood loss due to a negative suction effect. The use of tranexamic acid to reduce blood loss may nullify this. The aim of this study was to compare outcomes in patients undergoing total knee arthroplasty with or without drains and to analyze whether the drain's diameter also has an impact.

Methods: This is a prospective randomized study of patients undergoing unilateral total knee arthroplasty performed by a single surgeon. The study population was divided into three groups (A, 10G drain; B, 12G drain; and C, no drain). Pain, blood loss, swelling, wound-related complications, functional outcomes and questionnaire-based outcomes were assessed postoperatively.

Results: Each group had 35 patients comparable in most demographic and pre- and intraoperative characteristics. During the first 6 hours postoperatively, opioid consumption was significantly higher when the drain was not used $(p=0.036)$. At 3 months postoperatively, new Knee Society Score (NKSS) was highest with the use of $12 \mathrm{G}$ drain ( $p=0.018$ ). However, NKSS at 1 year was comparable across the three groups. With the use of tranexamic acid, blood loss and incidence of soakage of dressing were unaffected by the presence or absence of a drain. The calf girth, suprapatellar girth, soakage of dressing and range of motion were comparable in all three groups. There was no incidence of surgical site infection or deep vein thrombosis.

Conclusions: Presence of a suction drain significantly reduces opioid consumption during the first 6 hours after total knee arthroplasty. Use of a drain made no difference to the functional outcome at 1 year postoperatively. With the use of tranexamic acid in total knee arthroplasty, the total blood loss and the requirement of blood transfusion were unaffected by the presence or absence of closed suction drainage or by the bore of the drain used. The clinical parameters such as swelling, range of motion, infection and deep vein thrombosis also remained the same.

Keywords: Knee osteoarthritis, Arthroplasty, Drainage, Tranexamic acid

Received August 13, 2018; Accepted November 29, 2018

Correspondence to: Rajesh Navin Maniar, MCh (Ortho)

Department of Orthopaedics, Lilavati Hospital and Research Centre,

Bandra (West), Mumbai 400050, India

Tel: +91-22-26483391, Fax: +91-22-26407655

E-mail:drmaniar@jointspeciality.com
Intra-articular placement of a vacuum drain can reduce undesirable blood accumulation and thus prevent intraarticular or subcutaneous hematoma formation. ${ }^{1)}$ On the other hand, it can increase blood loss and the likelihood of postoperative blood transfusion. ${ }^{2)}$ Removal of drain is also associated with pain or sometimes breakage of drain tube requiring surgical removal. ${ }^{3)}$ The non-use of an indwelling vacuum drain, owing to a tamponade effect, can reduce 
Maniar et al. Drain in Knee Arthroplasty in Tranexamic Acid Era

Clinics in Orthopedic Surgery • Vol. 11, No. 1, $2019 \bullet$ www.ecios.org

total blood loss. ${ }^{4)}$ But it may lead to hematoma formation, pain, bleeding into dressings, wound tension, and hence slow down rehabilitation progress. ${ }^{5)}$ Despite the paucity of clinical evidence demonstrating any benefit supporting their use, intra-articular drains continue to be used after elective orthopedic procedures by many arthroplasty surgeons. ${ }^{6,7)}$ However, even amongst the surgeons favoring the use of drains, there is no standardization to the size of drain to be used. ${ }^{8)}$

Significant reduction in blood loss with the use of tranexamic acid (TxA), intravenous and local application, has now recently been well established. ${ }^{9,10)}$ This raises the question whether drains still have a beneficial role to play in modern day total knee arthroplasty (TKA) or whether the use TxA has made drains obsolete. Drains may still be useful in controlling swelling and preventing wound complications. Most of the literature on the use of drain in TKA is either from the pre-TxA era or remains silent on the impact of TxA on potential benefits of drains. There is scant literature on the use of drains in conjunction with use of TxA.

This study was undertaken with the aim to compare the results of closed suction wound drainage and no drainage in TKA when TxA is being used to minimize blood loss. This would also answer the question whether the use of TxA in TKA overcomes the shortcomings of not using a drain such as hematoma formation or frequent wound soakage. A secondary objective of the study was to compare results following the use of a small versus large bore drain. We hypothesize that the use or non-use of a drain will not make any difference to the postoperative pain, opioid consumption, blood loss, dressing-related complications, range of motion and questionnaire-based outcomes measure when current day techniques of minimizing blood loss, such as use of TxA, are employed.

\section{METHODS}

This prospective randomized study was conducted at a Breach Candy Hospital and Lilavati Hospital and Research Centre between May 2015 and May 2016, after obtaining Institutional Review Board and Ethics Committee approval (Project No. P1/2015). A pilot study of 45 patients was carried out to calculate the sample size and assess feasibility. Based on this pilot, keeping the two-sided confidence level at $95 \%$ and power of study as $80 \%$, we arrived at a minimum sample size requirement of $68 .{ }^{11)}$

During the period of the study, 135 patients that underwent unilateral primary TKA by a single surgeon (RNM) were considered for inclusion in the study. Of these, 105 patients were included in the study and the rest were excluded for the following reasons: 16 were on anticoagulants preoperatively; seven patients had a body mass index above $40 \mathrm{~kg} / \mathrm{m}^{2}$; four refused consent for participation in study; and three had inflammatory arthritis (Fig. 1). A written informed consent was obtained from all patients
135 Assessed for eligibility

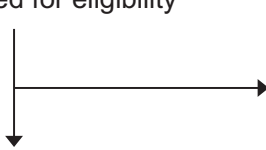

105 Randomized
30 Excluded

16 Use of anticoagulant

$7 \mathrm{BMI}>40 \mathrm{~kg} / \mathrm{m}^{2}$

4 Refused consent

3 Inflammatory arthritis
Allocation

Follow-up

( 2 weeks, 6 weeks, and 3 months)

Follow-up

(1 year)

Analysis

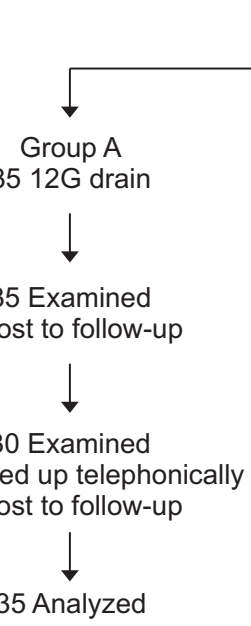

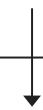

Group B

35 10G drain

35 Examined

0 Lost to follow-up

28 Examined

7 Followed up telephonically

0 Lost to follow-up

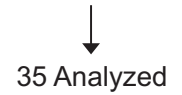

Group C

35 No drain

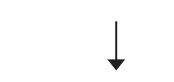

35 Examined

0 Lost to follow-up

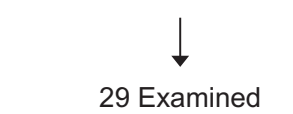

6 Followed-up telephonically

0 Lost to follow-up

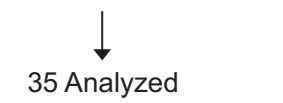

Fig. 1. Consolidated standards of reporting trials diagram depicting flow of study participants. 
authorizing radiological examination, photographic documentation, and surgery.

Routine preoperative work-up and review by an anesthetist was done 1 week prior to the surgery. Patients were explained the physiotherapy exercises preoperatively and hemoglobin level was checked 1 day prior to surgery. New Knee Society Score was used to assess preoperative status of the knee. They were then randomly allotted to one of the three groups based on a computer-generated randomization list. In group A, a $12 \mathrm{G}$ (4-mm) size vacuum suction drain was used, in group B a $10 \mathrm{G}(3.3-\mathrm{mm})$ size drain and in group $\mathrm{C}$ no drain was used. All three groups had 35 patients each.

All patients were operated by the same technique using PFC Sigma series of total knee prostheses (DePuy Orthopaedics Inc., Warsaw, IN, USA). All patients were operated under combined spinal and epidural anaesthesia (epidural catheter was removed after 24 hours). Intravenous antibiotics and $10 \mathrm{mg} / \mathrm{kg}$ TxA were administered half hour before tourniquet inflation. The tourniquet was inflated after exsanguination with Esmarch bandage before skin incision. The joint was exposed via a midline skin incision and medial parapatellar approach. Computerassisted navigation was used in all patients to achieve an accurate postoperative limb alignment. After cementing the components, the joint was soaked with $3 \mathrm{~g}$ of TxA in $100 \mathrm{~mL}$ of normal saline. Once cement hardened, the tourniquet was deflated and bleeders were cauterized. A $100-\mathrm{mL}$ cocktail of ketorolac (30 mg, $1 \mathrm{~mL}$ ), bupivacaine ( $0.5 \%$, volume in $\mathrm{mL}$ calculated as $40 \%$ of bodyweight), epinephrine $(5 \mu \mathrm{g} / \mathrm{mL}, 0.01 \mathrm{~mL} / \mathrm{kg}$ of body weight) and normal saline is used for periarticular injection. Out of this, $70 \mathrm{~mL}$ is injected into the deeper structures (posterior capsule, around collateral ligaments, quadriceps muscle and joint capsule) and $30 \mathrm{~mL}$ into superficial structures (subcutaneous tissue). At the end of operation; according to the group, drain of corresponding size (if patient belonged to group A or B) was inserted in the articular space with the other end coming out from a puncture on the lateral aspect of the distal thigh. For group $C$ patients, drain was not inserted. Closure of joint capsule, deep fascia, subcutaneous tissue and skin was done in layers by the same technique in all patients. A four-layered cotton gauze was used to cover the surgical site, after which the limb from mid-thigh to mid-leg was wrapped with a gamjee roll. The drain, if inserted, was clamped for initial 2 hours and then opened. The day of surgery was considered as day 0 . The next day was considered day 1 .

Patient-controlled analgesia with an infusion pump containing morphine $1 \mathrm{mg} / \mathrm{mL}$ was used for pain manage- ment. Apart from this, oral paracetamol $(1 \mathrm{~g}$, three times a day) and diclofenac suppositories (100 g, twice a day) were used for all patients. For the patients operated in the morning hours, the drain was removed next day afternoon at $12 \mathrm{pm}$. For the patients operated after $12 \mathrm{pm}$, the drain was removed on the next day, 24 hours after closure, at 4 $\mathrm{pm}$. Change of dressing was done on day 1 morning which included cleaning of wound by chlorhexidine solution and then applying four layers of cotton gauze maintaining the same thickness of dressing for all patients.

Patients who were operated in the morning were mobilized on the same day evening and those operated in the afternoon were mobilized the next day morning. Subcutaneous low molecular weight heparin $(4,000 \mathrm{IU}$ or $40 \mathrm{mg}$ ) was given once a day from day 1 till the day of discharge and below knee compression stockings were used as deep vein thrombosis (DVT) prophylaxis. Patients were shifted to oral anticoagulant (rivaroxaban, $10 \mathrm{mg}$ daily) at the time of discharge, which was then continued till suture removal ( 2 weeks). Intravenous antibiotics were continued till day 1. Hemoglobin levels were assessed on day 1 and day 3. Knee bending at the edge of bed was started from day 2 and straight leg raising was assessed on day 3. A skin marking pen was used to mark the points for measurement of suprapatellar girth $(2 \mathrm{~cm}$ above the superior pole of patella) and calf girth ( $2 \mathrm{~cm}$ below tibial tuberosity). These measurements were then taken daily on the marked points. Range of motion, pain on visual analog scale (VAS), soakage of dressing and ecchymosis were also noted down daily till discharge. During the period of admission and on subsequent follow-up visits, calf tenderness was noted as part of postoperative assessment. Any patient with calf tenderness and an increase in girth measurement was investigated further by a venous color Doppler to look for DVT. Temperature charting was maintained for all patients while admitted in the hospital. Fever beyond postoperative day 2 , rise in leucocyte counts, rising trend of inflammatory markers (erythrocyte sedimentation rate and C-reactive proteins) and discharge from surgical site were considered as indicators of surgical site infection and warranted aspiration of the knee to confirm infection.

Blood transfusion was indicated in patients with hemoglobin levels less than $8 \mathrm{mg} / \mathrm{dL}$ and who had developed symptoms such as tachycardia, tachypnea or decreased exercise tolerance postoperatively despite having hemoglobin levels between $8 \mathrm{mg} / \mathrm{dL}$ and $10 \mathrm{mg} / \mathrm{dL}$. Clinical evaluation and hemoglobin levels were re-evaluated 6 weeks after the surgery.

For calculation of the total blood loss by the hemoglobin balance method, the patient's blood volume was 
first calculated using the formula of Nadler et al. ${ }^{12)}$ as follows: patient's blood volume $=(\mathrm{k} 1 \times$ height $3[\mathrm{~m}])+(\mathrm{k} 2 \times$ weight $[\mathrm{kg}])+\mathrm{k} 3$; where $\mathrm{k} 1=0.3669, \mathrm{k} 2=0.03219$, and $\mathrm{k} 3$ $=0.6041$ for male and $\mathrm{k} 1=0.3561, \mathrm{k} 2=0.03308$, and $\mathrm{k} 3$ $=0.1833$ for female. The loss of hemoglobin then was estimated according to the following formula: Hbloss $=$ patient's blood volume $\times(\mathrm{Hbi}-\mathrm{Hbe}) \times 0.001+\mathrm{Hbt}$, where Hbloss (g) was the amount of hemoglobin lost up to day 3 after surgery, $\mathrm{Hbi}(\mathrm{g} / \mathrm{L})$ was the hemoglobin concentration before surgery, Hbe $(\mathrm{g} / \mathrm{L})$ was the hemoglobin concentration on the third day after surgery, and $\mathrm{Hbt}(\mathrm{g})$ was the amount of hemoglobin transfused. ${ }^{13,14)}$ From these, the total blood loss in milliliters was calculated as follows: total blood loss $=1,000 \times$ Hbloss $/ \mathrm{Hbi}{ }^{15,16)}$

All patients were followed at 2 weeks, 6 weeks, 3 months and 1 year from the surgery. There was no loss to follow-up till 3 months from the surgery. However, 18 patients (17\%) were unable to come for their 1-year followup. Although we could not record the functional status and NKSS of these patients, we did contact them telephonically to enquire about status of the knee and presence of any signs or symptoms of surgical site infection. All 18 patients were satisfied with the outcome of their surgery and had not developed any signs or symptoms of infection.

Statistical analysis was carried out using SPSS ver. 15.0 (SPSS Inc., Chicago, IL, USA). Data were given as mean and standard deviation for quantitative data and number (\%) for qualitative data. Student unpaired $t$-test was applied to compare means between two groups. Anal- ysis of variance (or F-test) was applied to compare means of three groups. Chi-square test was applied to compare percentages among three groups. All statistical tests were two tailed. Level of significance $(\alpha)$ was taken as $p=0.05$.

\section{RESULTS}

\section{Demographics, Pre- and Intraoperative Characteristics}

The demographics, pre- and intraoperative characteristics of these groups are depicted in Table 1. The groups were comparable in all aspects except with regard to gender distribution and incidence of thyroid disorders. Intraoperative variables of tourniquet time, pressure, and duration of surgery were also comparable between the three groups.

\section{Pain}

Consumption of morphine during the first 6 hours after the surgery was significantly higher $(p=0.036)$ when no drain was used (Table 2). Post-hoc analysis by Tukey test revealed that the significant difference lay between group A (12G drain) and group C (no drain). This was in spite of the fact that all patients received the same periarticular analgesic cocktail prior to closure. However, morphine consumption 6-24 hours and 24-48 hours and total consumption were comparable between the three groups. Even subjective assessment of pain via VAS did not differ significantly amongst the groups on day $1,2,3$, or 4 .

Table 1. Demographics, Comorbidities, and Relevant Intraoperative Parameters

\begin{tabular}{|lcccc|}
\hline \multicolumn{1}{|c}{ Variable } & Group A & Group B & Group C & $p$-value \\
\hline Age (yr) & 70.5 & 70.6 & 69.7 & 0.873 \\
\hline Male:female & $5: 30$ & $10: 25$ & $2: 33$ & 0.032 \\
\hline Body mass index $\left(\mathrm{kg} / \mathrm{m}^{2}\right)$ & 28.8 & 27.9 & 28.6 & 0.534 \\
\hline Diabetes mellitus $(\%)$ & 14.3 & 22.9 & 25.7 & 0.474 \\
\hline Hypertension $(\%)$ & 60 & 80 & 65.7 & 0.178 \\
\hline Thyroid disorder $(\%)$ & 17.1 & 25.7 & 2.9 & 0.027 \\
\hline Range of motion $\left({ }^{\circ}\right)$ & $3.2-124.1$ & $2-121.7$ & $2.3-124.8$ & 0.475 \\
\hline Hemoglobin $(\mathrm{gm} / \mathrm{dL})$ & 12.2 & 12.3 & 12 & 0.576 \\
\hline Tourniquet pressure $(\mathrm{mmHg})$ & 290.3 & 288 & 286.3 & 0.363 \\
\hline Tourniquet time $(\mathrm{min})$ & 66.5 & 63.4 & 66.8 & 0.387 \\
\hline Duration of surgery $(\mathrm{min})$ & 126.7 & 124.7 & 124 & 0.787 \\
\hline
\end{tabular}

Quantitative variables are presented as mean and comorbidities are presented as prevalence.

Group A: $12 \mathrm{G}$ (4-mm) size vacuum suction drain group, Group B: 10G (3.3-mm) size drain group, Group C: no drain group. 
Table 2. Parameters Indicative of Pain

\begin{tabular}{|lcccc|}
\hline \multicolumn{1}{c}{ Variable } & Group A & Group B & Group C & $p$-value \\
\hline Morphine consumed 0-6 hours (mg) & 4.1 & 4.4 & 6.5 & $0.036^{*}$ \\
\hline Morphine consumed 6-24 hours (mg) & 5.4 & 5.5 & 6.7 & 0.442 \\
\hline Morphine consumed 24-48 hours (mg) & 4.1 & 5.2 & 5.2 & 0.569 \\
\hline Total morphine consumption (mg) & 13.6 & 15 & 18.4 & 0.245 \\
\hline VAS day 1 & 2.1 & 2.7 & 2.5 & 0.203 \\
\hline VAS day 2 & 2.5 & 3 & 2.6 & 0.299 \\
\hline VAS day 3 & 2.3 & 2.6 & 2.5 & 0.826 \\
\hline VAS day 4 & 2.1 & 2.2 & 2.1 & 0.858 \\
\hline
\end{tabular}

Total morphine consumption was also highest in patients without drain, but the difference was not statistically significant. All variables are presented as mean values.

Group A: 12G (4-mm) size vacuum suction drain group, Group B: 10G (3.3-mm) size drain group, Group C: no drain group, VAS: visual analog scale.

*Morphine consumption during the first 6 hours after surgery showed a significant difference in three group analysis. Post-hoc analysis revealed that this significant difference lay between group $\mathrm{A}$ and group $\mathrm{C}$.

Table 3. Total Blood Loss and Loss in Drain

\begin{tabular}{lcccc}
\hline \multicolumn{1}{c}{ Variable } & Group A & Group B & Group C & $p$-value \\
\hline Drain loss 0-6 hours $(\mathrm{mL})$ & 97.3 & 77.4 & NA & 0.800 \\
\hline Drain loss 6-24 hours $(\mathrm{mL})$ & 149.5 & 146 & NA & 0.142 \\
\hline Total drain loss $(\mathrm{mL})$ & 246.7 & 223.4 & NA & 0.341 \\
\hline Total blood loss $(\mathrm{mL})$ & 706.4 & 770.4 & 707.8 & 0.777 \\
\hline
\end{tabular}

Group A: 12G (4-mm) size vacuum suction drain group, Group B: 10G (3.3-mm) size drain group, Group C: no drain group, NA: not applicable.

\section{Blood Loss}

Total blood loss calculated by the hemoglobin balance method was comparable between the three groups (Table 3). Use of a $10 \mathrm{G}$ or $12 \mathrm{G}$ drain made no significant difference to the total blood loss in the drain. Even when blood loss in the drain was analyzed separately for the first 6 hours and 6-24 hours, there was no significant difference between $10 \mathrm{G}$ and $12 \mathrm{G}$ drains. Only two patients in the study received a blood transfusion, one in group $\mathrm{A}$ and one in group $\mathrm{C}$.

\section{Swelling and Dressing}

The three groups had a comparable trend of rise and fall of suprapatellar and calf girth measurements (Fig. 2). In group A $17.1 \%$ patients and in group B $11.4 \%$ patients developed blood soakage of dressing over the drain exit site. Dressing over the surgical site developed blood soakage in $14.2 \%, 11.4 \%$, and $14.2 \%$ of patients in groups A, $\mathrm{B}$, and $\mathrm{C}$, respectively. These differences in the incidence of soakage of drain site dressing and surgical site dressing were not statistically significant $(p=0.494$ and $p=0.921$, respectively). None of the patients in the study developed a surgical site infection or DVT.

\section{Range of Motion and Straight Leg Raising}

The use of 10G/12G drain or not using a drain at all did not make a difference to the range of motion achieved at 2 weeks, 6 weeks, and 3 months postoperatively (Fig. 3 ). At the end of 3 months, all three groups showed mild improvement in the mean range of flexion as compared to the preoperative range. None of the patients needed manipulation under anesthesia postoperatively. On day 3, active straight leg raising was possible in $22.8 \%$ patients in group A, $28.5 \%$ in group B, and $40 \%$ in group C. This difference though was found to be statistically not significant $(p=0.284)$. 
Maniar et al. Drain in Knee Arthroplasty in Tranexamic Acid Era

Clinics in Orthopedic Surgery • Vol. 11, No. 1, $2019 \bullet$ www.ecios.org

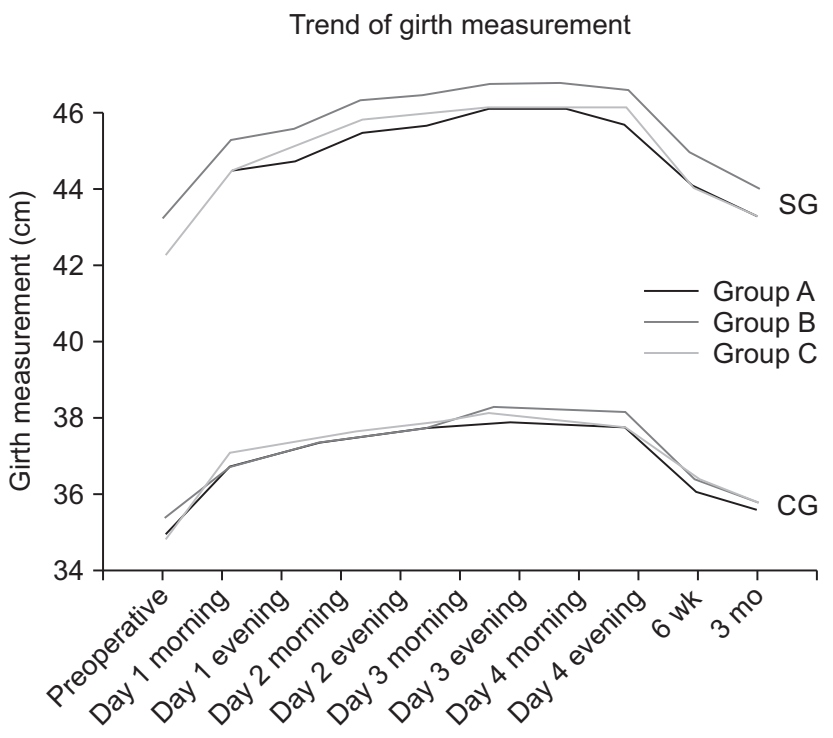

Fig. 2. Line diagram illustrating the trend of increase and subsequent decrease in suprapatellar (SG) and calf (CG) girth measurements from 1 day before surgery to 3 months after surgery. Trend of girth measurements is comparable in groups $A, B$, and C. Group $A: 12 G(4-m m)$ size vacuum suction drain group, Group B: 10G (3.3-mm) size drain group, Group C: no drain group.

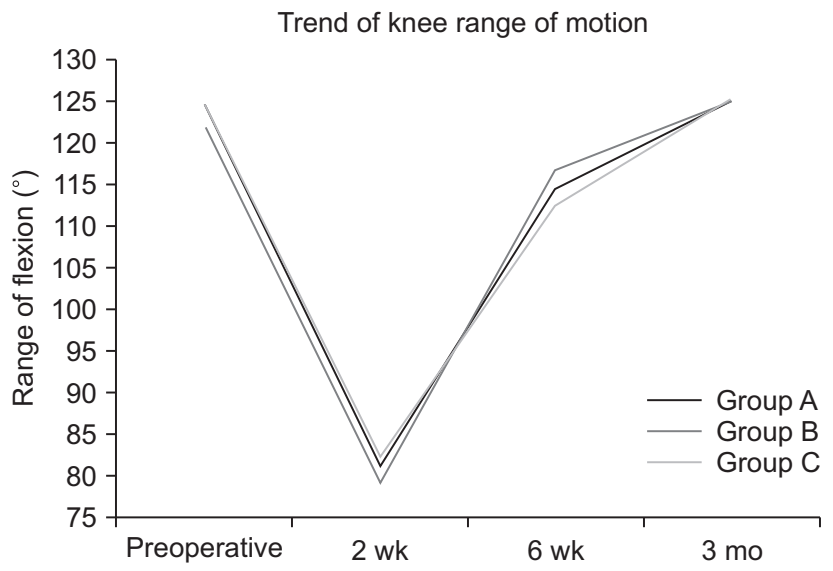

Fig. 3. Line diagram illustrating the decline and subsequent regaining of flexion at the knee after surgery. No significant differences were observed in the trend of knee range of motion between the three groups.

Table 4. New Knee Society Score and Its Subcomponents

\begin{tabular}{|ccccc|}
\hline Variable & Group A & Group B & Group C & $p$-value \\
\hline Preoperative & & & & 0.438 \\
\hline NKSS & $101.5(29.9)$ & $109.9(23.6)$ & $103.9(24.9)$ & 0.195 \\
\hline OKS & $43.7(16.5)$ & $50.2(19.4)$ & $43.9(13.9)$ & 0.908 \\
\hline FS & $31(14.3)$ & $30.3(13.4)$ & $32.2(15.1)$ & 0.690 \\
\hline ESS & $26.9(6.5)$ & $28.5(8.7)$ & $28.3(6.8)$ & $0.018^{*}$ \\
\hline At 3 months & & & & 0.095 \\
\hline NKSS & $184.6(18.7)$ & $171(23.2)$ & $177.2(24.3)$ & 0.061 \\
\hline OKS & $93.3(12.2)$ & $88.3(11.2)$ & $91.4(4.2)$ & 0.276 \\
\hline FS & $51.8(8.7)$ & $45.1(11.1)$ & $48.8(15.9)$ & $37.9(7.8)$ \\
\hline ESS & $40.4(6.6)$ & $37.6(11.3)$ & & 0.202 \\
\hline At 1 year & & & $190.1(26.4)$ & 0.667 \\
\hline NKSS & $191(15.7)$ & $187(28.2)$ & $96.7(5.9)$ & 0.794 \\
\hline OKS & $95.6(3.8)$ & $96.6(4.7)$ & $54.1(17)$ & 0.461 \\
\hline FS & $52.8(13.9)$ & $51(20.4)$ & $39(7.1)$ & \\
\hline ESS & $41.1(6.5)$ & $39(8.7)$ & & \\
\hline
\end{tabular}

Values are presented as mean scores (standard deviation). Preoperative scores were comparable among the groups. At 3 months after surgery, patients with a $12 \mathrm{G}$ drain had a significantly higher NKSS. The outcome scores at 1 year after surgery were comparable.

Group A: $12 \mathrm{G}(4-\mathrm{mm})$ size vacuum suction drain group, Group B: 10G (3.3-mm) size drain group, Group C: no drain group, NKSS: new Knee Society Score, OKS: objective knee score, FS: functional score, ESS: expectation and satisfaction score.

${ }^{*}$ The 3 -month postoperative NKSS was significantly better in group A. Post-hoc analysis revealed that the significant difference lay between groups $\mathrm{A}$ and $\mathrm{B}$ and between groups $\mathrm{A}$ and $\mathrm{C}$. 


\section{New Knee Society Score}

Preoperatively, NKSS and its sub-components were comparable between the three groups (Table 4). At 3 months, the groups remained comparable in the expectation score, function score and objective knee score but differed significantly in total NKSS $(p=0.018)$. Group receiving a $12 \mathrm{G}$ drain had a higher NKSS at 3 months as compared to the other two groups. At 1-year review, NKSS and its sub-components did not vary significantly amongst the three groups in the 87 patients who completed their 1-year follow-up.

\section{Infection and DVT}

None of the patients in the study developed a surgical site infection or DVT.

\section{DISCUSSION}

The most important finding of the study was the significantly higher amount of opioid consumption during the first 6 hours after the surgery, when no drain was used. Minimization of opioid consumption in the immediate postoperative period should lead to a decrease in the incidence and morbidity of opioid associated adverse effects. Patients in whom drains were used had a significantly lower opioid consumption during the first 6 hours after surgery. This reflects that the use of drain decreases immediate postoperative pain. However, we could not support this observation by VAS, since it was recorded 24 hours after the surgery.

Most of the demographics and preoperative parameters of the three groups in this study were comparable. The groups were not comparable only in terms of distribution of gender and thyroid disorders. However, gender has clearly been proven to have no impact on hemoglobin loss or opioid consumption post-TKA. ${ }^{17,18)}$ Prior to surgery, all patients diagnosed with thyroid disorders were ensured to be euthyroid. Thus, we postulate that uneven distribution of gender and thyroid disorders did not impact our results.

We hypothesize that in the absence of a drain, hematoma formation occurs during the first few hours postoperatively, leading to stretching of knee capsule and pain sensitive structures around the knee. This in turn produces pain, leading to higher consumption of mor-

Table 5. Summary of Comparative Studies on the Use of Drain in TKA Published in the Last 5 Years

\begin{tabular}{|c|c|c|c|}
\hline Author (year)/journal & No. of patients & TxA & Conclusion \\
\hline $\begin{array}{l}\text { Watanabe et al. }(2016)^{191} / \\
\text { J Arthroplasty }\end{array}$ & $\begin{array}{l}63 \text { Bilateral TKA patients: } \\
\text { 20, drain on both sides; } 21 \text {, no drain; } \\
\text { 22, drain on one side }\end{array}$ & $\begin{array}{l}1 \mathrm{~g} \text { of TxA (10 mL) injected into joint } \\
\text { either via drain or injection after closure }\end{array}$ & $\begin{array}{l}\text { Drop in hemoglobin is significantly } \\
\text { lower when drain is not used. No } \\
\text { differences in range of motion } \\
\text { between the groups. }\end{array}$ \\
\hline Chen $(2016)^{4} / /$ nt Orthop & $\begin{array}{l}\text { 575, With drains; } 902 \text {, } \\
\text { without drain; multiple surgeons }\end{array}$ & $\begin{array}{l}\text { Joint soaked for } 5 \text { minutes with } \\
1.5 \mathrm{~g} \text { in } 100 \mathrm{~mL} \text { saline }\end{array}$ & $\begin{array}{l}\text { Greater total blood loss when } \\
\text { drain is used. Comparable 30-day } \\
\text { readmission rate and incidence of } \\
\text { additional surgical procedure. }\end{array}$ \\
\hline $\begin{array}{l}\text { Wang et al. }(2016)^{201} / \\
\text { Orthop Surg }\end{array}$ & $\begin{array}{l}80 \text { Patients: } 40 \text {, with drain; } \\
\text { 40, without drain }\end{array}$ & $\begin{array}{l}15 \mathrm{mg} / \mathrm{kg} \text { of TxA injected intravenously } \\
\text { before tourniquet deflation }\end{array}$ & $\begin{array}{l}\text { Better knee range of motion, early } \\
\text { regaining of active straight leg } \\
\text { raising in patients without drain. } \\
\text { Comparable total blood loss } \\
\text { between the two groups. }\end{array}$ \\
\hline This study (2018) & $\begin{array}{l}105 \text { patients: } 35,10 \mathrm{G} \text { drain; } \\
35,12 \mathrm{G} \text { drain; } 35 \text {, no drain }\end{array}$ & $\begin{array}{l}10 \mathrm{mg} / \mathrm{kg} \text { of TxA was intravenously } \\
\text { injected } 30 \text { minutes before tourniquet } \\
\text { inflation and the joint was soaked with } \\
3 \mathrm{~g} \text { of TxA in } 100 \mathrm{~mL} \text { saline after } \\
\text { cementation. }\end{array}$ & $\begin{array}{l}\text { Decreased opioid consumption in the } \\
\text { first } 6 \text { hours postoperatively when } \\
\text { drain is not used. Comparable blood } \\
\text { loss in all three groups. Better } \\
\text { NKSS at } 3 \text { months postoperatively } \\
\text { with } 12 \mathrm{G} \text { drain, but no difference } \\
\text { at } 1 \text { year from surgery. }\end{array}$ \\
\hline
\end{tabular}


phine. Measurement of suprapatellar girth at 6 hours from the surgery might have shown a significant increase when no drain was used. In the study, girth measurements were made 24 hours after the surgery, which did not show any significant difference between the groups. In groups A and $\mathrm{B}$, we clamped the drains for 2 hours after closure to produce a tamponade effect in order to reduce blood loss.

Recent literature on the use of suction drains postTKA presents a divided opinion. A summary of such recent studies has been provided in Table 5 . These studies have focused on blood loss, range of motion and functional outcome. de Andrade et al. ${ }^{5}$ reported better functional outcome in the early postoperative period with the use of drain, whereas Wang et al. ${ }^{20)}$ reported better early functional outcome without the use of drain. Complete functional recovery post-TKA, however, can take up to 1 year. At 1 year postoperatively, the three groups in our study were comparable in terms of functional status. Higher blood loss with the use of drains was reported by Watanabe et al. ${ }^{19)}$ and Chen et al. ${ }^{4)}$ in spite of intra-articular application of TxA in both studies, whereas Wang et al. ${ }^{20}$ concur with our finding that with the use of TxA, blood loss remains unaffected by the presence or absence of a drain. None of these studies have been able to highlight a difference in opioid consumption pattern between patients with drains and those without such as in our study.

This study was limited by its relatively small sample size due to strict inclusion criteria and limited time duration available for the study. Although recent single surgeon-based studies on this topic have a similar sample size (Table 5), we maintained an aggressive follow-up to compensate for this shortcoming. We were able to follow all patients till 3 months postoperatively and $83 \%$ of the patients till 1 year postoperatively. Telephonic enquiries were made by one of the authors (RB) for the remaining $17 \%$ who could not be followed up at 1 year. Thus, we were able to gather that all patients were satisfied with the status of their knee and none of them had developed a surgical site infection. Another limitation of the study was that since the patients were discharged on the morning of day 4 , we did not pursue them to get their day 5 hemoglobin levels. Keeping patients admitted for an extra day, for the purpose of this study, would lead to unnecessary social and financial burden on them, while also increasing their chances of acquiring nosocomial infection. However, a uniform protocol of measuring the hemoglobin levels on day 1 and day 3 was followed for all patients.

Presence of a suction drain significantly reduces opioid consumption during the first 6 hours after TKA. Use of a wide bore (12G) drain has a better functional outcome at 3 months postoperatively; however, the use of drain makes no difference to the functional outcome at 1 year postoperatively. With the use of TxA in TKA, the total blood loss and the requirement of blood transfusion are unaffected by the presence or absence of closed suction drainage or by the bore of the drain used. The clinical parameters such as swelling, range of motion, infection and DVT also remain the same.

\section{CONFLICT OF INTEREST}

No potential conflict of interest relevant to this article was reported.

\section{REFERENCES}

1. Mirzatolooei F, Tabrizi A, Gargari MM. A comparison of the postoperative complications between two drainage methods after total knee arthroplasty. Arch Bone Jt Surg. 2018;6(1):47-51.

2. Raja A, Manzoor H, Jan WM, Assad S. Comparison between closed suction drainage and no drainage following total knee arthroplasty in a tertiary care setting in Pakistan. Cureus. 2016;8(10):e842.

3. Cox JS, Friess D. Retained surgical drains in orthopedics: two case reports and a review of the literature. Case Rep Orthop. 2017;2017:8194571.

4. Chen JY, Lee WC, Chan HY, Chang PC, Lo NN, Yeo SJ. Drain use in total knee arthroplasty is neither associated with a greater transfusion rate nor a longer hospital stay. Int
Orthop. 2016;40(12):2505-9.

5. de Andrade MA, de Oliveira Campos TV, Silva BF, et al. Six month follow-up of patients submitted to total knee arthroplasty with and without placement of suction drainage devices. Rev Bras Ortop. 2015;45(6):549-53.

6. Zhang Q, Liu L, Sun W, et al. Are closed suction drains necessary for primary total knee arthroplasty? A systematic review and meta-analysis. Medicine (Baltimore). 2018;97(30):e11290.

7. Si HB, Yang TM, Zeng Y, Shen B. No clear benefit or drawback to the use of closed drainage after primary total knee arthroplasty: a systematic review and meta-analysis. BMC Musculoskelet Disord. 2016;17:183. 
8. Leao MG, Neta GM, Silva TM, Ferreira YM, Dias WR. Does the suction drain diameter matter? Bleeding analysis after total knee replacement comparing different suction drain gauges. Rev Bras Ortop. 2016;51(5):547-54.

9. Maniar RN, Kumar G, Singhi T, Nayak RM, Maniar PR. Most effective regimen of tranexamic acid in knee arthroplasty: a prospective randomized controlled study in 240 patients. Clin Orthop Relat Res. 2012;470(9):2605-12.

10. Ishida K, Tsumura N, Kitagawa A, et al. Intra-articular injection of tranexamic acid reduces not only blood loss but also knee joint swelling after total knee arthroplasty. Int Orthop. 2011;35(11):1639-45.

11. Kelsey JL, Whittemore AS, Evans AS, Thompson WD. Methods of sampling and estimation of sample size. In: Kelsey JL, Whittemore AS, Evans AS, Thompson WD, eds. Methods in observational epidemiology. 2nd ed. New York: Oxford University Press; 1996. 311-40.

12. Nadler SB, Hidalgo JH, Bloch T. Prediction of blood volume in normal human adults. Surgery. 1962;51(2):224-32.

13. Fahmy NR, Patel DG. Hemostatic changes and postoperative deep-vein thrombosis associated with use of a pneumatic tourniquet. J Bone Joint Surg Am. 1981;63(3):461-5.

14. Langdown AJ, Field J, Grote J, Himayat H. Aprotinin (Trasylol) does not reduce bleeding in primary total hip arthroplasty. J Arthroplasty. 2000;15(8):1009-12.

15. Good L, Peterson E, Lisander B. Tranexamic acid decreases external blood loss but not hidden blood loss in total knee replacement. Br J Anaesth. 2003;90(5):596-9.

16. Lisander B, Ivarsson I, Jacobsson SA. Intraoperative autotransfusion is associated with modest reduction of allogeneic transfusion in prosthetic hip surgery. Acta Anaesthesiol Scand. 1998;42(6):707-12.

17. Boutsiadis A, Reynolds RJ, Saffarini M, Panisset JC. Factors that influence blood loss and need for transfusion following total knee arthroplasty. Ann Transl Med. 2017;5(21):418.

18. Pope D, El-Othmani MM, Manning BT, Sepula M, Markwell SJ, Saleh KJ. Impact of age, gender and anesthesia modality on post-operative pain in total knee arthroplasty patients. Iowa Orthop J. 2015;35:92-8.

19. Watanabe T, Muneta T, Yagishita K, Hara K, Koga H, Sekiya I. Closed suction drainage is not necessary for total knee arthroplasty: a prospective study on simultaneous bilateral surgeries of a mean follow-up of 5.5 years. J Arthroplasty. 2016;31(3):641-5.

20. Wang $\mathrm{D}, \mathrm{Xu} \mathrm{J}$, Zeng WN, et al. Closed suction drainage is not associated with faster recovery after total knee arthroplasty: a prospective randomized controlled study of 80 patients. Orthop Surg. 2016;8(2):226-33.

21. Yin D, Delisle J, Banica A, et al. Tourniquet and closed-suction drains in total knee arthroplasty: no beneficial effects on bleeding management and knee function at a higher cost. Orthop Traumatol Surg Res. 2017;103(4):583-9. 